\title{
Bricolage research in history education as a scholarly mixed-methods design
}

\author{
Heather Sharp* - University of Newcastle, Australia
}

\begin{abstract}
Research using a mixed-methods design is increasingly becoming the norm, crossing the myriad of educational fields of research, including history education. While commonly interpreted as a combining of qualitative and quantitative methods, mixed methods in history education can also extend to a bricolage approach, whereby the epistemological aspect of research is explicitly used to frame a study incorporating a combination of interdisciplinary methodologies and theoretical underpinnings. It extends beyond the often asserted binary of qualitative and quantitative research. In considering directions of qualitative research in the broad discipline area of education, the work of researchers such as Kincheloe (2005) and Denzin and Lincoln (2005) is used throughout this paper within a qualitative research context based on the work of Kincheloe and Tobin (2006). Adopting their approach of investigating the complexity of the lived world means placing research within a number of contexts. Research can be framed - from conceptualization to data gathering to analysis - in a range of contexts, appropriately matched between stage of research and underpinning theories. This paper reports on how bricolage can be used to frame research in history education.
\end{abstract}

Keywords: bricolage; history education; mixed methods; research methodology; researcher subjectivities

\section{Introduction}

This paper provides a theoretical reflection on mixed-methods research design through a carefully curated bricolage design to analyse and report data. Internationally, many tertiary research environments currently emphasize a metrics approach to research and are-some may say, overly and unduly - concerned with outputs in terms of publications, grant funding, and supervising research higher degree students. Quantitative methods are prioritized in a research culture that rewards science, technology, engineering and maths (STEM) over creative arts, business, law and education (CABLE). Despite the funding and university hierarchy preference for research that favours quantitative outputs, it remains important for those in non-STEM disciplines to develop new, and refine existing, research methodologies that are not limited by current political and, funding - trends. This paper addresses the importance of undertaking rigorous and innovative research practices by analysing the theoretical underpinnings of the bricolage approach to methodology.

While much research literature on the topic of mixed methods focuses on the differences - often viewed as a divide - between qualitative and quantitative data, this paper approaches mixed methodologies from the perspective of a bricolage 
approach, one where multiple qualitative approaches are used in combination. One of the benefits of using bricolage is that it can be tailored to suit each individual project. The larger research project on which this paper draws encompassed aspects of a variety of research fields (education and history being the most prominent) and methodological approaches, with critical discourse analysis (CDA) as the lead methodology, and incorporating contributions from visual analysis and historical methodology. In bricolage, approaches are selected that complement each other so that the research method, data collection and analysis are strengthened. The deployment of a hotchpotch methodology is a criticism that could potentially be made of a bricolage approach when it is not grounded with a strong theoretical base, but is avoided by ensuring that the selected approaches epistemologically complement each other. This paper engages with Johnson et al.'s (2007: 112) work, which seeks a 'dialogue and social construction of a workable definition' as 'a worthwhile goal for the field' by considering mixed-methods research beyond the qualitative and quantitative binary and investigating the complexities of an approach that encompasses theoretical underpinnings that are made explicit to the reader. Discussing the need to ensure there is a context of knowledge in reporting on research in the field of education, Kincheloe and Tobin (2006: 5) write:

In the epistemological domain we begin to realize that knowledge is stripped of its meaning when it stands alone. This holds profound implications in education and research because more positivistic forms of educational science have studied the world in a way that isolates the object of study, abstracts it from the contexts and interrelationships that give it meaning. Thus, to be a critical researcher that takes the complexity of the lived world into account, we have to study the world 'in context.'

Similar to mixed-method research design being, as described by Riazi and Candlin (2014: 139) a pragmatic decision-making matter of 'what is appropriate and "what works" in relation to specific research questions and the contexts in which they are being asked', bricolage can also be viewed as a pragmatic approach to research, with an explicit critical turn. With an intention to engage in criticality, the variety of approaches that can be incorporated makes bricolage versatile and attractive to consider for researchers undertaking research projects that require a move away from a singular research methodology.

\section{Bricolage as methodology}

An effective bricolage mixed-methodology approach can be formed using a combination of interdisciplinary methodologies and theoretical grounding across a variety of complementary fields. The methodologies explained here are examples of how to curate a coherent mixed methodology in history education research, particularly one that seeks to analyse historical representations in, for example, school curriculum texts or student responses to sources (see, for example, Sharp, 2012). They include critical discourse analysis (CDA), itself an interdisciplinary approach, and visual analysis techniques, combined with a historical methodological approach and framed by Gramsci's $(1957,1971)$ and Althusser's $(1971,1984)$ notions of hegemony, ideology and power. Within a rigorous approach, this enables a 'research eclecticism, allowing circumstances to shape the methods employed' (Kincheloe, 2008a: 322).

Bricolage methodology encompasses more than is implied in the literal French translation of the word - a common starting place for descriptions of bricolage - of 
being a Jack (or Jill) of all trades using collected materials at hand in construction. A bricoleur - the name given to a researcher engaging in this type of research - is defined by Lévi-Strauss (1966: 17) as a 'Jack of all trades or a kind of professional do-it-yourself person'. More than this, 'the bricoleur produces a bricolage, that is, a pieced-together, close-knit set of practices that provide solutions to a problem in a concrete situation ... that changes and takes new forms as different tools, methods, and techniques are added to the puzzle' (Denzin and Lincoln, 1998: 3).

A researcher bricoleur carefully selects the most appropriate methodology available that will strengthen the research being conducted. This approach 'involves the process of rigorously rethinking and reconceptualizing multidisciplinary research ... Employing these multiperspectival (Kellner, 1995) dynamics, bricoleurs ... open new windows onto the world of research and knowledge production' (Kincheloe, 2008b: 4). More than a traditional mixed-methodology approach to research, bricolage applies the most appropriate research methodology to different sections of the same research, 'employing ... strategies when the need arises in fluid research situations' (ibid.), with the researcher being explicit about the social and political perspectives they take in constructing and applying a methodology.

Contemporary understandings of bricolage can be traced to Lévi-Strauss's (1966) seminal publication, The Savage Mind. It is from here that Denzin and Lincoln (1994, 2000), Kincheloe (2001, 2005) and Kincheloe and Berry (2004) begin articulating their own understanding of bricolage as an important component for reconceptualizing qualitative research. Reflecting on the work of Denzin and Lincoln, Kincheloe writes, 'bricolage is typically understood to involve the process of employing these methodological strategies as they are needed in the unfolding context of the research situation' (Kincheloe and Berry, 2004: 2). This first way that Kincheloe sees bricolage is the way it is applied in this research, viewing rigorous methodologies in terms of moving from a 'monological knowledge' (ibid.: 23) base and way of seeing research, to being able to construct a variety of approaches into one, coherent methodology, suited to a specific research project. Given that bricoleurs select from a range of methodologies, philosophies and theories to construct a rigorous methodology for a specific research project, it is reasonable to expect that each time a bricoleur conducts research, a different combination of approaches may be adopted. This can be situated within a critical multiplism that, as Johnson et al. (2007: 116) point out, occurs from the point at which 'research questions can be examined from different perspectives and it is often useful to combine different methods with different biases'. It sees that a singular method is not always appropriate for the various stages of a research project, from question formation, to data gathering, to analysis, to reporting, to drawing conclusions, and all the other components of research in between these major project milestones.

This paper advocates a bricolage that combines existing, established methodological approaches in order to arrive at the strongest, most rigorous methodology possible for the research undertaken. Therefore, this research is not concerned with the second way that Kincheloe (2005: 324) sees bricolage may be applied:

Appreciating research as a power-driven act, the researcher-as-bricoleur abandons the quest for some naive concept of realism, focusing instead on the clarification of his or her position in the web of reality and the social locations of other researchers and the ways they shape the production and interpretation of knowledge. 
Rather, the use of bricolage is seen as occurring on a continuum of application, with its purpose being to articulate an overt awareness of the interconnectedness of research methodology, methods, broader historical contexts and analysis of findings, so that a valid research project can be conducted that connects research to current and historical sociopolitical environments. This fits with Johnson et al.'s (2007: 113) assertion that mixed-methods research is 'an approach to knowledge (theory and practice) that attempts to consider multiple viewpoints, perspectives, positions, and standpoints (always including the standpoints of qualitative and quantitative research)'.

\section{Disclosure of researcher}

The background of the researcher is an issue taken seriously within a bricolage approach, beyond a tokenistic statement of the background relationship between the researched and the researcher. Researcher disclosure has a long history. The renowned twentieth-century historian E.H. Carr (1961: 5) emphasizes the importance for readers to study the background of the researcher, through his well-known Trevelyan lectures, recorded in What is History?:

When we attempt to answer the question, What is history?, our answer, consciously or unconsciously, reflects our own position in time, and forms part of our answer to the broader question, what view we take of the society in which we live.

However, E.H. Carr stops short of advising researchers themselves to offer this information in a self-critique to readers, but rather presents it as an opportunity for readers of history to engage in further research about historians, their backgrounds, and lived environment and contexts. Another British historian, Arthur Marwick (2001: 2), develops this perspective, arguing that 'writers and teachers should always state their fundamental assumptions, and readers and students should always seek to find out what these are'.

What bricolage offers in the discussion about disclosure of researchers is a structured and theoretical base to provide this information in meaningful ways, embedded within the research methodology, rather than as an afterthought. As Denzin and Lincoln (1994: 3) explain, 'the bricoleur understands that research is an interactive process shaped by ... personal history, biography, gender, social class, and ethnicity'. Theories from other disciplines concerned with the disclosure of the researcher, such as Gee's (2004) frame problem from a literacy discipline and Hexter's (1971) second record from a history discipline can also be incorporated. Berry (2006: 90) also emphasizes the need for researchers to position themselves within the context of their research, stating:

For contemporary research content and processes such as bricolage, identifying how and why the researcher is positioned in the study is a must. Shifting positionalities (based on place, time, gender, race, class, sexuality etc.) from which a researcher reads, writes, analyzes, indicate a recognition of the part played by the socializing texts of scholarly discourses, academic expectations and contexts throughout time and space. 


\section{Bricolage as interdisciplinary}

Taking the view that a single research methodology is not always sufficient to enable effective data analysis, the following sentiments of Kellner, as summarized by Kincheloe and Berry (2004: 52) holds true for this particular research, being: 'that any single research perspective is laden with assumptions, blindnesses, and limitations. To avoid one-sided reductionism ... researchers must learn a variety of ways of seeing and interpreting in the pursuit of knowledge'. The use of bricolage enables a variety of approaches, theories and philosophies to be drawn on in the process of constructing a strong methodology tailored to suit the requirements of specific research projects. Considering bricolage in this way demonstrates that it 'views research methods actively rather than passively, meaning that we actively construct our research methods' (ibid.: 2). In discussing the use of a variety of methodological approaches in his work, Van Leeuwen asserts that 'every good "applied" project challenges the theory. No "toolkit" can ever be used without adaptation and modification' (Reitstaetter et al., 2005: 9). Just as importantly, Berry (2006: 88) points out that in selecting a variety of methodological approaches, 'you don't use all the parts', instead the researcher selects aspects of each methodology in ways to ensure that the research process maintains strong principles of investigation.

Just as cultural studies emerged as 'the product of a critical reflex based on dissatisfaction in which philosophy, linguistics, literary criticism, sociology, anthropology, psychology, history and the like, were leading institutionally separated lives of their own' (Verschueren, 2001: 65), bricolage can be seen to have emerged as a way to bring together methodological silos, to ensure that appropriate approaches can be combined when one, distinct methodology does not best serve the purposes of research. Additionally, similar to cultural studies, which in the view of Verschueren (ibid.: 66), looks beyond 'disciplinary boundaries, constraints and vested interests', the same can be said for bricolage in terms of taking a methodological, rather than a disciplinary approach to research.

Using a form of bricolage enables a more rigorous methodology to emerge than would otherwise be possible by only using (for example) CDA or only using historical research and ignoring important theoretical understandings related to power, ideology, discourse construction and knowledge acquisition. By stepping beyond imposed disciplinary boundaries, a combination methodology is used that prevents 'rationalistic fragmentation ... [that] undermines our ability to derive the benefits of multiple perspectives' (Kincheloe and Berry, 2004: 41). Doing so strengthens data analysis and findings, and can result in 'providing new knowledge, insights, ideas, practices, structures that move towards social justice, inclusiveness, diversity, plurality and so forth' (Berry, 2006: 90).

Those who use the type of bricolage advocated in this paper are likely to concur with the statement made by Johnson et al. (2007: 125) that:

Many (or most) mixed methods writers have argued for some version of pragmatism as the most useful philosophy to support mixed methods research ... Pragmatism offers an epistemological justification (i.e., via pragmatic epistemic values or standards) and logic (i.e., use the combination of methods and ideas that helps one best frame, address, and provide tentative answers to one's research question[s]) for mixing approaches and methods. A pragmatist would reject an incompatibility thesis and would claim that research paradigms can remain separate, but they also can be mixed into another research paradigm. 


\section{Five dimensions of bricolage}

In taking the view that bricolage is an extension of multi-method research and triangulation, this paper draws on the work of Denzin and Lincoln (2005) and Kincheloe (2005). Denzin and Lincoln (2005: 2) explain that 'qualitative research is inherently multimethod in focus.... The combination of multiple methods, empirical materials, perspectives and observers in a single study is best understood, then, as a strategy that adds rigor, breadth, and depth to any investigation.' The focus on connections between methodologies is evident through the five dimensions of bricolage. These five dimensions, conceptualized by Denzin and Lincoln (2000), are used by Berry (2006) and Kincheloe (2005), who extend and more finely articulate them. The five dimensions, 'methodological bricolage, theoretical bricolage, interpretive bricolage, political bricolage, and narrative bricolage' (ibid.: 335) are applied in this project as shown in Table 1. Berry (2006: 96) succinctly describes the five dimensions: 'bricoleurs need to access multiple theories (theoretical bricolage), research genres and conventions (methodological bricolage), ways to interpret (interpretive bricolage) and ways of reporting/telling the story (narrative bricolage)'. Combined, they provide a specific philosophical research approach, and Table 1 provides an example of how bricolage can be successfully applied to a research project.

Table 1: Five dimensions of bricolage

\begin{tabular}{ll}
\hline Approach & Application in this research \\
\hline Methodological & $\begin{array}{l}\text { Critical discourse analysis (CDA) } \\
\text { Visual analysis (incorporating a CDA approach to analysing images) } \\
\text { Historical methodology }\end{array}$ \\
\hline $\begin{array}{l}\text { Theoretical } \\
\text { bricolage }\end{array}$ & $\begin{array}{l}\text { Poststructuralist analysis of texts } \\
\text { Gramsci (1957, 1971) and Althusser (1971, 1984): notions of ideological } \\
\text { power and hegemony }\end{array}$ \\
\hline Interpretive & $\begin{array}{l}\text { Disclosure of researcher, incorporating aspects of personal 'lived context' } \\
\text { (Kincheloe, 2005: 336) }\end{array}$ \\
bricolage & Contexts: situating the research within its historical time period \\
\hline Political & $\begin{array}{l}\text { Gramsci and Althusser through curriculum hegemony } \\
\text { bricolage }\end{array}$ \\
$\begin{array}{l}\text { Apple (2000): official knowledge } \\
\text { Issues of national identity through school curriculum }\end{array}$ \\
\hline Narrative & An historical narrative is constructed aligned within a qualitative approach \\
bricolage & to report data findings \\
\hline
\end{tabular}

\section{Bricolage and history education}

An important reason for adopting a bricolage approach to history education research (even with CDA being the leading and dominant methodology), is to make a concerted effort to overcome potential criticisms of methodological weaknesses that could be lodged if only a singular approach is used (see, for example, Schegloff, 1997, 1998, 1999). Used this way, bricolage strengthens a variety of approaches. Ensuring that the bricolage approach is grounded in theoretical understanding avoids a potential hotchpotch of methodological ideas, with no links to each other, and ensures that 'the methods ... serve the aims of the research, not [that] the research serve[s] the aims of the method' (Pink, 2001: 4).

In many ways, bricolage is still an experimental methodology, particularly in the field of history education. Drawing on a variety of methodologies, theories and 
philosophies, the way it is being applied in qualitative research is emerging as a new frontier of knowledge construction, with increasing moves against research embedded only in positivist paradigms. Bricoleurs are thus able to undertake research 'freed from reductionistic conventions in ways that facilitate their moves not to an anything-goes model of research but to genuinely rigorous, informed multiperspectival ways of exploring the lived world' (Kincheloe, 2005: 337). At this point in its history, however, bricolage remains on the fringe of accepted norms of research in history education. With increased use and adaptation, it will potentially become more accepted across a number of research fields, including, as already seen, in social sciences, environmental studies, education and business studies. This project, therefore, presents a modest attempt at bricolage. There is further ground to be gained in order to start to integrate reconceptualizations of methodologies and improvisation into this type of research. However, by combining only a small number of approaches, processes of further engagement and experimentation begin, and, as explained by Lévi-Strauss (1966: 18), 'aspects of different methodological approaches are integrated, not so that each 'of them ... have only one definite and determinate use ... [but rather they] each represent a set of actual and possible relations; they are "operators" but they can be used for any operations of the same type'. In discussing qualitative research and bricolage as a type of multi-methods research, Denzin and Lincoln (2005: 5) affirm:

Qualitative research is inherently multi-method in focus (Flick, 2002: 226-227) ... The combination of multiple methodological practices, empirical materials, perspectives, and observers in a single study is best understood, then, as a strategy that adds rigor, breadth, complexity, richness, and depth to any inquiry ...

Bricolage, then, is used as a way to enrich the findings that emerge from the data by enabling a variety of methodological, theoretical and philosophical approaches to be adopted and adapted to suit the requirements of the research, while still 'maintain[ing] theoretical coherence and epistemological innovation' (Kincheloe and McLaren, 2005: 316). Doing so frees the research from conforming uncomfortably to one, set, methodological tool that could potentially compromise the data gathering and analysis, thus avoiding 'a reductionistic form of knowledge that impoverishes our understanding of everything connected to it' (Kincheloe and Berry, 2004: 5). As Kincheloe and McLaren (2005: 316) write: 'in the first decade of the 21 st century, bricolage typically is understood to involve the process of employing these methodological strategies as they are needed in the unfolding context of the research situation'. Bricolage, then, can be viewed as an organizer of the methodological approaches used in the various stages of a project.

\section{Researcher subjectivities}

Rather than being seen as an unconditionally negative component of research, the explication of potential prejudices and research subjectivities is an opportunity to position the researcher (in this case, rather than research) within a clearly articulated framework. Doing so provides opportunities for subjectivities and other potential conflicts of interest to be openly discussed and made known to the reader, and, in a sense, as Lather (cited in McKenzie, 2005: 403) describes, a 'de-centering of the author' takes place. A further subjectivity to consider is what Derrida terms a researcher's 'textual heritage' (Berry, 2006: 87) in relation to research methodologies. Applied to

a bricolage approach, Derrida (cited in ibid.) demonstrates the importance of the 
researcher clearly framing disclosures, 'the activity of borrowing from one's own textual heritage whatever is needed to produce new and different texts, with an emphasis on intertextual borrowing for the purposes of textual construction'. These approaches take into consideration the following statement by Telles (2000: 252):

My past as a student, teacher, and artist was linked to my focus of interest in the subject-matter of the thesis - teacher education and critical language awareness. Intuitively, I sensed that many links existed. Making them explicit was the challenging task of the reflection through which I went during the research process.

Telles critiques his researcher subjectivities as a way to strengthen his qualitative researcher approach. Disclosing potential conflicts of interest attached to the perspective, experiences and similar factors of the researcher, enables a more located reading of the findings so that integrity and validity of findings is maintained. This is referred to by Gee (2004: 30) as the 'frame problem'. Gee describes this in relation both to analyses of the parts of data collected through research and to researchers disclosing information about themselves as relevant to the research. A bricolage approach also considers disclosures of the researcher as an important part of ensuring that rigour is maintained, and discusses this within a philosophical framework of researchers understanding and being explicit about their social world. As historian E.H. Carr (1961) describes, the environmental factors of the researcher's (in this context, the historian's) background, thus assist 'bricoleurs [to] bracket their own subjectivity as researchers' (Kincheloe and Berry, 2004: 8).

Regarding the issue of the politics of the researcher, Verschueren (2001: 66) explains the importance of adequate disclosure, asserting that by not consciously considering and communicating disclosures, researchers open themselves to legitimate criticism regarding their approach:

... the delicate balance between scientific and social values requires that, though a pre-existent perspective, point of view or ideology cannot - and should not - be abstracted when engaging in research activities, specific social and political commitments should be linked to scientific authority only if they follow from, not guide, the research. In order to safeguard the relevance of anchoring research in social and political reality, it must be possible for the research and its conclusions to receive the epithet 'critical' without their necessarily being conducted and formulated - as often seems to be the case now - by scholars with professed and welldefined political commitments.

Furthermore, it is helpful to keep in mind Flowerdew's (1999: 1096) assertion that analysis is 'susceptible to multiple interpretations' and is 'the result of an individual' (ibid.: 1097). 'Inevitably,' Flowerdew continues, 'it will be marked by the individual sensibilities and style of the author.' It is also important to make clear and obvious personal interactions or background information that the researcher has about data that has been collected and analysed. Described as 'invisible to the reader', this information should be made apparent to ensure that integrity is retained and disclosures of the researcher are evident. This is echoed in, and aligned with, the work of researchers such as Blommaert (2001: 16), who asserts that the contextualizing of texts used for data collection is vital for a comprehensive analysis to take place: 
This is the 'context' for the rest of the analysis, and this context is offered as an unquestionable, untheorized set of 'facts'. The source of such contextual accounts is often obliquely referred to as on-site observation ... (again, untheorized and without discussing any explicit procedures). Their function, however, is crucial: they are central contextualising features that allow for claims about an 'insiders' perspective'.

Blommaert (ibid.) emphasizes this, as he considers that many researchers do not adequately (if at all) offer a critical contextual explanation of how, or from where, data emerge, and claims that such information is kept from the reader, and made known to the researcher only, to the detriment of the research validity.

My context in selecting bricolage is that I originally qualified as a history and English teacher, and now work in the tertiary sector. My knowledge and experiences in English teaching led me to select CDA as an approach, as I am very aware of the power that language has to influence learning, and to inform and persuade readers through selection of words, positioning of phrases, and omission and inclusion of content, particularly within the context of the educational curriculum. This makes it even more important to ensure that the theoretical groundings of the methodology are clearly outlined. Doing this will avoid what Parker and Burman (1993: 161) describe as researchers 'who already have some political sense and can recognize its relevance and scope ... know already that language contains and reinforces ideology ... simply generated the analysis that makes sense to them in a fairly atheoretical, but politically informed, way'. Instead, analysis is conducted using a strong theoretical understanding, and political perspectives on the conduct of historical research are substantially disclosed.

As an experienced researcher in the area of history textbooks, and having been a history teacher, the use of textbooks in teaching is very familiar to me, both personally (as a teacher) and professionally (as a researcher). However, the relationship between the textbooks selected for this case study and the researcher is somewhat removed, as the texts investigated and analysed were not ever personally used in the classroom and the selection of what constitutes 'history' textbooks has been predetermined by the teachers who used them in the classroom, the publishers and curriculum developers. In addition, the relationship is further removed as the textbooks were used in the past; therefore, there is no personal investment based on school experience of using the selected school curriculum texts. This avoids some of the reflexivity issues that Rogers (2004: 250) raises about educational researchers working within familiar settings, which may lead us to 'bring with us histories of participation within these institutions as students, teachers ...'.

\section{Case study: The 1988 Bicentennial of British colonization}

History education is a large field of enquiry with an array of projects that suit varying methodologies. Not all history education research lends itself to bricolage, and it could be argued that it is better suited either to large projects that have multiple data sources or to those that investigate historical representations. The case study presented here is from a project that drew on a large number and type of sources, some traditionally the sources of historical work and others that are arguably more in the field of political science or other humanities fields. The project, which was an investigation of the school history curriculum, spanned several specified eras within 
a one-hundred-year period, and drew on: educational materials that were used as both primary sources in a traditional historical methodological way and to frame the sociopolitical context of the selected era; educational materials that are either - or both - word-based or image-based; government policy documents; public discourses that were used as historical primary sources, such as media reports, advertisements, speeches by key people such as politicians, Hansard reports, history books (providing a secondary source of information), literary fiction and samples from popular culture. Using this data, it was necessary to be able to understand historical sociopolitical contexts that varied between the selected time periods, and to be able to 'read' the data in different ways, depending on type and context. Additionally, in looking at historical representations rather than reporting on or writing a traditional history, the project needed to find ways to report on the data in authentic ways. In doing this, and in adhering to bricolage approaches, theoretical understandings were made explicit ones that often remain in the background of research (especially in historical research). For example, explicitly making a statement about the frames in which data is analysed, rather than it being presented as a benign or 'natural' selection.

For the larger study from which this paper draws, historical periods were selected to demonstrate the connection between public discourses and school history curriculum content, and illuminated through British heritages and Indigenous representations. The historical periods were characterized by two features: first, when major historical or social events occurred within a short time frame, creating an identifiable shift in public discourses; and second, when a new or revised syllabus was implemented in schools. Three specific areas of focus that meet these characteristics are: the period just prior to and just after the First World War; the Australian Black Movement 1964-75; and the 1988 Bicentennial of British colonization. Each era was significant for quite different reasons, but with the common factor that they have been important in the history of Australia, and continue to be so in terms of constructions of national identity.

The case study on multiculturalism reported here is from the time of the 1988 Bicentennial of British colonization: 1788 marked the arrival of the British ships on the Australian continent known as the First Fleet, and this act has been described variously as settlement, colonization, occupation and invasion. Using a CDA approach to the analysis, it is argued that overall, there was a celebratory discourse surrounding the Bicentennial, with little regard in official discourses for the perspectives of the Indigenous peoples of Australia. Analysis of data determined that the political context of multiculturalism featured strongly in the school curriculum, and this impacted the type of history taught to students. It frequently adopted a vague, social studies approach to historical narratives in an attempt to be inclusive, Australia having emerged from the post-White Australia policy era that framed much of the immigration practices until the early to mid-1970s. Analysing the various historical and contemporaneous sources meant that a variety of methodological approaches were deployed in order to get a deep understanding of the sociopolitical milieu of the time, and to be able to frame that within a historical context. Accordingly, CDA was selected as the primary analytical tool, incorporating Kress and Van Leeuwen's (2006) work on visual analysis techniques, combined with historical methodology, and framed by Gramsci's $(1957,1971)$ and Althusser's (1971, 1984) notions of hegemony, ideology and power. The eclecticism discussed earlier in this paper enabled a rigorous analysis using the selected methods.

Through a careful reading of the school curriculum data, using the various approaches, it was found that, by and large, representations of individuals and groups of people who do not fit within narrow Anglo-Australian constructs adhered to stereotypical ideas of how these people behave and the activities in which they engage. 
(For a more detailed report of this case study, with a focus on CDA, see Sharp, 2012.) Therefore, a type of multicultural exotica results, whereby Anglo-Australian cultures are constructed as banal and of the everyday, and all other cultures are portrayed as exciting and elusive. As a result of this, Anglo-Australians are positioned as belonging to one cultural group, void of any complexity.

Analysis of the curriculum materials for this era demonstrates that topics and concepts related to historical knowledge are not consistently or strongly evident. Instead, any celebratory discourses of Australian history focus on multiculturalism, at the expense of, for example, both British heritages and Indigenous representations. Aspects of early modern Australian history that cover British heritages are generally either ignored or significantly mitigated through a vague discourse of 'European' settlement. Indigenous representations, particularly in the primary curriculum, demonstrate an ahistorical representation of Indigenous Australians. This potentially leads to an inaccurate representation of national history being taught to school students.

The type of multiculturalism presented in the school curriculum separated cultures outside of the Anglo-Australian mainstream, firmly placing people of distinct ethnic origins to be represented only through special days and events. There are several clear messages that demonstrate this type of multiculturalism, endorsed through the social studies curriculum. First, although diverse groups of peoples are included in the curriculum, they do not form part of the core curriculum, and are only visible during special events and celebrations that are usually add-ons to the curriculum - to be included if there is time, or if teachers have the inclination, what Apple (2000: 53) refers to as 'mentioning':

Dominance is partly maintained here through compromise and the process of 'mentioning'. Here, limited and isolated elements of the history and culture of less powerful groups are included in the texts. Thus, for example, a small and often separate section is included on 'the contribution of women' and 'minority groups', but without any substantive elaboration of the view of the world as seen from their perspectives.

Second, only Anglo-Australians are depicted doing everyday activities, such as civictype duties, playing sport and shopping. Combined with the first point, this ensures that people who are not Anglo-Australian are seen as a type of exotica. Steinberg (2010) argues that popular culture frequently sees non-dominant groups in this way. Third, multiculturalism is a complex concept, with many diverse definitions of what it means and how it should be enacted - it was seen this way in the 1980s, just as much as it is now. Therefore, to present it in such a simplistic way is to miss potential key teaching moments that introduce students to its complexities.

What has been presented here is only one aspect of the case study, selected to emphasize the usefulness of using bricolage in a project on historical representations using a large number and a variety of sources. The conclusions about multiculturalism in the school curriculum would not have been reached without a thorough understanding of the sociopolitical context of the time, without understanding the historical context of education in Australia, and without a sense of the history of racism and privileging whiteness in Australia's immigration law. A rigorous methodology that understands differences in written and visual texts also enhanced the analysis, and ensured that the images contained in the school curriculum were not missed. The five types of bricolage outlined in Table 1 - methodological, theoretical, interpretive, political and 
narrative - were addressed in the methodology, and enabled a more thorough analysis than if, for example, only CDA or only historical methodology had been used.

\section{Conclusion}

To conclude, a feature of a strong qualitative approach to research, as espoused by Denzin and Lincoln (2005: 376) is that 'although qualitative researchers may design procedures beforehand, designs always have built-in flexibility, to account for new and unexpected empirical materials and growing sophistication'. This is supported by Kincheloe and McLaren (2005: 317), who write that 'bricolage views research methods actively rather than passively, meaning that we actively construct our research methods from the tools at hand rather than passively accepting the "correct" universally applicable methodologies'.

What has been presented in this paper is an approach to mixed-methods research that encompasses a range of approaches that researchers can use to construct the best possible research project. With a focus away from the traditional qualitative versus quantitative dichotomy, researchers can gain confidence in selecting the appropriate methods at different stages of their project.

\section{Notes on the contributor}

Heather Sharp is a senior lecturer in the Faculty of Education and Arts, University of Newcastle, Australia. Her research investigates historical representations, particularly around topics of significance to a nation's history. Heather is a founding member of the HERMES research group. She is Convener of the History Network for Teachers and Researchers (HNTR), Editor of the Sungrapho section of the Agora journal, and the Special Issues Editor of Historical Encounters Journal.

\section{References}

Althusser, L. (1971) Lenin and Philosophy, and Other Essays. Trans. Brewster, B. London: New Left Books.

Althusser, L. (1984) Essays on Ideology. London: Verso.

Apple, M.W. (2000) Official Knowledge: Democratic education in a conservative age. 2nd ed. New York: Routledge.

Berry, K.S. (2006) 'Research as bricolage: Embracing relationality, multiplicity and complexity'. In Tobin, K. and Kincheloe, J.L. (eds) Doing Educational Research: A handbook. Rotterdam: Sense Publishers, 87-115.

Blommaert, J. (2001) 'Context is/as critique'. Critique of Anthropology, 21 (1), 13-32.

Carr, E.H. (1961) What is History? New York: Vintage Books.

Denzin, N.K. and Lincoln, Y.S. (eds) (1994) Handbook of Qualitative Research. Thousand Oaks, CA: SAGE Publications.

Denzin, N.K. and Lincoln, Y.S. (eds) (1998) The Landscape of Qualitative Research: Theories and issues. Thousand Oaks, CA: SAGE Publications.

Denzin, N.K. and Lincoln, Y.S. (eds) (2000) Handbook of Qualitative Research. 2nd ed. Thousand Oaks, CA: SAGE Publications.

Denzin, N.K. and Lincoln, Y.S. (eds) (2005) The SAGE Handbook of Qualitative Research. 3rd ed. Thousand Oaks, CA: SAGE Publications.

Flowerdew, J. (1999) 'Description and interpretation in critical discourse analysis'. Journal of Pragmatics, 31 (8), 1089-99.

Gee, J. P. (2004) 'Discourse analysis: What makes it critical?'. In Rogers, R. (ed.) An Introduction to Critical Discourse Analysis in Education. Mahwah, NJ: Lawrence Erlbaum Associates, 19-50.

Gramsci, A. (1957) The Modern Prince, and Other Writings. Trans. Marks, L. New York: International Publishers. 
Gramsci, A. (1971) Selections from the Prison Notebooks of Antonio Gramsci. Ed. and trans. Hoare, Q. and Nowell Smith, G. London: Lawrence and Wishart.

Hexter, J.H. (1971) The History Primer. New York: Basic Books.

Johnson, R.B., Onwuegbuzie, A.J. and Turner, L.A. (2007) 'Toward a definition of mixed methods research'. Journal of Mixed Methods Research, 1 (2), 112-33.

Kincheloe, J.L. (2001) 'Describing the bricolage: Conceptualizing a new rigor in qualitative research'. Qualitative Inquiry, 7 (6), 679-92.

Kincheloe, J.L. (2005) 'On to the next level: Continuing the conceptualization of the bricolage'. Qualitative Inquiry, 11 (3), 323-50.

Kincheloe, J.L. (2008a) 'Bricolage and the quest for multiple perspectives'. In Fong, T.P. (ed.), Ethnic Studies Research: Approaches and perspectives. Lanham, MD: AltaMira Press, 313-51.

Kincheloe, J.L. (2008b) 'Critical pedagogy and the knowledge wars of the twenty-first century'. International Journal of Critical Pedagogy, 1 (1), 1-22.

Kincheloe, J.L. and Berry, K.S. (2004) Rigour and Complexity in Educational Research: Conceptualizing the bricolage. Maidenhead: Open University Press.

Kincheloe, J.L. and McLaren, P. (2005) 'Rethinking critical theory and qualitative research'. In Denzin, N.K. and Lincoln, Y.S. (eds) The SAGE Handbook of Qualitative Research. 3rd ed. Thousand Oaks, CA: SAGE Publications, 303-42.

Kincheloe, J.L. and Tobin, K. (2006) 'Doing educational research in a complex world: Preface'. In Tobin, K. and Kincheloe, J.L. (eds) Doing Educational Research: A handbook. Rotterdam: Sense Publishers, 3-13.

Kress, G. and Van Leeuwen, T. (2006) Reading Images: The grammar of visual design. 2nd ed. London: Routledge.

Lévi-Strauss, C. (1966) The Savage Mind. London: Weidenfeld and Nicolson.

Marwick, A. (2001) The New Nature of History: Knowledge, evidence, language. Basingstoke: Palgrave.

McKenzie, M. (2005) 'The "post-post period" and environmental education research'. Environmental Education Research, 11 (4), 401-12.

Parker, I. and Burman, E. (1993) 'Against discursive imperialism, empiricism, and constructionism: Thirty-two problems with discourse analysis'. In Burman, E. and Parker, I. (eds) Discourse Analytic Research: Repertoires and readings of texts in action. London: Routledge, 155-72.

Pink, S. (2001) Doing Visual Ethnography: Images, media and representation in research. London: SAGE Publications.

Reitstaetter, J., Rheindorf, M. and Van Leeuwen, T. (2005) 'Media discourse: Social semiotics and the study of multimodal discourse'. Reconstruction: Studies in Contemporary Culture, 5 (2), 1-10.

Riazi, A.M. and Candlin, C.N. (2014) 'Mixed-methods research in language teaching and learning: Opportunities, issues and challenges'. Language Teaching, 47 (2), 135-73.

Rogers, R. (2004) 'Setting an agenda for critical discourse analysis in education'. In Rogers, R. (ed.) An Introduction to Critical Discourse Analysis in Education. Mahwah, NJ: Lawrence Erlbaum Associates, 237-54.

Schegloff, E.A. (1997) 'Whose texts? Whose context?'. Discourse and Society, 8 (2), 165-87.

Schegloff, E.A. (1998) 'Reply to Wetherell'. Discourse and Society, 9 (3), 413-16.

Schegloff, E.A. (1999) "'Schegloff's texts" as "Billig's data": A critical reply'. Discourse and Society, $10(4), 558-72$.

Sharp, H. (2012) 'Australia's 1988 bicentennial: National history and multiculturalism in the primary school curriculum'. History of Education, 41 (3), 405-21.

Steinberg, S.R. (2010) 'Islamophobia: The viewed and the viewers'. In Kincheloe, J.L., Steinberg, S.R. and Stonebanks, C.D. (eds) Teaching against Islamophobia (Counterpoints 346). New York: Peter Lang, 79-97.

Telles, J.A. (2000) 'Biographical connections: Experiences as sources of legitimate knowledge in qualitative research'. Qualitative Studies in Education, 13 (3), 251-62.

Verschueren, J. (2001) 'Predicaments of criticism'. Critique of Anthropology, 21 (1), 59-81. 